\title{
JUSTIFICAR A POLÍTICA: A ÉTICA COMO PRIMEIRA LIÇÃO
}

\author{
André Brayner de Farias \\ Universidade de Caxias do Sul
}

RESUMO: A tensão que se observa no pensamento de Levinas entre ética e ontologia reflete no contraste inevitável entre o tempo da ética e o tempo da política. Mas é preciso entender tal contraste levando em consideração o conceito de temporalidade diacrônica. A primazia da ética face à ontologia e à política é diacrônica, mas há um plano, o da visibilidade e realização histórica, onde ética e política se encontram. Em outras palavras, a incondicionalidade ética levinasiana, imemorial, pré-original, não poderá se realizar senão nas condições instituídas pela história e pela política. Daí decorre o entendimento de que a política e suas instituições devem assumir como tarefa histórica um processo permanente de justificação, mediante a retomada de sua primeira e mais fundamental lição, a ética.

Palavras-chave: Ética, Política, Ontologia, Tempo diacrônico.

RESUME: La tension dans la pensée de Levinas entre éthique et ontologie se reflète dans le contraste inévitable entre le temps de l'éthique et le temps de la politique. Mais il faut comprendre ce contraste en prenant en compte le concept de temporalité diachronique. La primauté de l'éthique sur l'ontologie et la politique est diachronique, mais il existe un plan, celui de la visibilité et de la réalisation historique, où l'éthique et la politique se rencontrent. Autrement dit, l'inconditionnalité éthique levinasienne, pré-originale, immémoriale, ne peut être réalisée que dans les conditions établies par l'histoire et la politique. D'où la compréhension que la politique et ses institutions doivent assumer comme tâche historique un processus permanent de justification, par la reprise de sa leçon première et la plus fondamentale, l'éthique.

Mots-clés: Éthique, Politique, Ontologie, Temps diachronique. 
Question par excellence ou la question de la philosophie. Non pas: pourquoi l'être plutôt que rien, mais comment l'être se justifie. (Emmanuel Levinas, Éthique comme philosophie première, p. 109)

\section{Certamente é mérito da filosofia levinasiana uma compreensão crítica e} radical de nosso mal-estar face a ordem política do mundo. Porque nos habituamos a manter um certo "pé atrás" diante da política, dos políticos ou dos assuntos políticos, ou, antes ainda, porque no fundo não nos conformamos com a ideia real da política - segundo Levinas "a arte de ganhar a guerra" ${ }^{1}$ e segundo Foucault "a continuação da guerra por outros meios" ${ }^{2}$ - diante de nossa incurável insistência em imaginar ou projetar o seu ideal. Que a política siga sendo um projeto frustrado, irrealizado ou, na melhor das hipóteses, mal realizado, é que, no fundo, intuímos

\footnotetext{
${ }^{1}$ A citação é do prefácio de Totalité et infini: "A arte de prever e de ganhar por todos os meios a guerra - a política - se impõe, desde então, como o exercício mesmo da razão. A política se opõe à moral, como a filosofia à ingenuidade". (LEVINAS, Emmanuel. Totalité et infini. Essai sur l'extériorité. Paris: Kluwer Academic, 2000. p. 5. Tradução livre). A radicalidade dessa posição é marcante e, em geral, está na memória dos leitores de Levinas. A política é o instrumento par excellence da guerra, de maneira tal que, diante dela, a moral só pode ser algo irrisório e ingênuo. Mas se resta, diante de tal constatação, de tal perplexidade, alguma dignidade para seguir filosofando, é preciso empreender o esforço de recuperar a própria dignidade da política. É preciso começar de novo, por outro caminho: enfatizar a exterioridade como absoluto, como incondicional, a ponto de interromper o funcionamento conceitual da política como instrumento de guerra, cujo conceito é a própria totalização ("Rien n'est dès lors extérieur", conforme lemos na página 6 do prefácio). A questão ética terá de ser o imperativo da política: como criar um mundo que afirme e dignifique em cada instante seu a prevalência da exterioridade? Como criar um mundo pautado pelo princípio da infinitude ética do outro?
}

${ }^{2}$ Trata-se em Foucault, da inversão da tese de Clausewitz sobre a guerra, segundo a qual a guerra é a continuação da política por outros meios. "E, se é verdade que o poder político pára a guerra, faz reinar ou tenta fazer reinar uma paz na sociedade civil, não é de modo algum para suspender os efeitos da guerra ou para neutralizar o desequilíbrio que se manifestou na batalha final da guerra. $O$ poder político, nessa hipótese, teria como função reinserir perpetuamente essa relação de força, mediante uma espécie de guerra silenciosa, e de reinseri-la nas instituições, nas desigualdades econômicas, na linguagem, até nos corpos de uns e de outros. Seria, pois, o primeiro sentido a dar a essa inversão do aforismo de Clausewitz: a política é a guerra continuada por outros meios; isto é, a política é a sanção e a recondução do desequilíbrio das forças manifestado na guerra". (FOUCAULT, Michel. Em defesa da sociedade. São Paulo: Martins Fontes, 2002. p. 23). Em lugar de armas e derramamento explícito de sangue, a politica com suas instituições e leis, dispositivos para uma guerra silenciosa e jamais declarada. 
que sempre falta para ela, ou faltamos para com ela, realizar a sua primeira e mais fundamental lição: a ética. O lugar comum de que o problema da política é a falta de ética ganha na filosofia de Levinas um modo sofisticado de articulação: o lugar mais original do pensamento não é o do saber perfeitamente adequado ao ser, mas o de uma passividade ou de uma inquietude onde o ser é constantemente levado a se justificar.

Se falta ética na política, não é propriamente porque a política está descumprindo um acordo que bastaria observar e fazer valer, sendo tal acordo forjado no horizonte político e, necessariamente, condicionado aos domínios da ação política. Essa compreensão retira da ética o seu caráter fundamental, promovendo um reducionismo que só interessa à política na medida em que ela pode se justificar por ela mesma. Se a ética se reduz a protocolos, sempre haverá formas de cumprilos, ainda que sua falta permaneça recorrente. Uma política que se justifica por ela mesma pode perfeitamente se contentar com uma ética protocolar, que nunca ultrapassará a condição de caricatura da ética.

A compreensão que precisa ser produzida é a de que a falta de ética na política interrompe o próprio nascimento da política. Uma política onde falta ética rigorosamente não mereceria ser chamada de política porque sequer teve a ocasião de vir a ser. Obviamente que isso não condiz com nenhuma realidade política conhecida, não condiz com a realpolitik. Uma compreensão levinasiana da política deve nos levar a entender a condição política como processo permanente de produção, nascido e nascendo de uma situação ética perpetuamente originária. Essa situação originária e originante destitui a ontologia de seu reinado metafísico ${ }^{3}$. Porque o ser e não o nada é uma

\footnotetext{
${ }^{3}$ A crítica da ontologia constitui o aspecto desconstrutor da filosofia levinasiana. Mas é preciso evitar uma recorrente interpretação dialética da questão, onde a afirmação da ética dependeria da negação do ser. A alteridade ética, articulada pelo conceito de infinito, não nega o ser, mas introduz em seu discurso um dispositivo de problematização. Não há como ontologizar o conceito de infinito, sem o qual não há como falar em ética. Por outro lado, a própria materialidade discursiva ou a própria efetividade da ética depende da ontologia. Esse é o ponto crítico do discurso de Levinas, e ele foi dissecado por Jacques Derrida no artigo Violence et métaphysique, em 1964. O impasse da ética da alteridade é uma questão de linguagem, impossível de ser resolvida. Resulta daí que o discurso ético e ontológico ou ético-político só pode ser um discurso problematizante, cuja habilidade será criar zonas de tensão, brechas por onde uma inesperada justiça encontra sua ocasião de acontecer.
} 
questão demasiadamente precipitada para incitar o início do pensamento. Uma questão que padece de uma miopia congênita e incurável, que só vai se sofisticando a medida que vai se alimentando de novas versões de si mesma. E se a linguagem que temos à disposição se orienta pelo verbo ser, esse talvez seja mais um motivo para querer sair do ser. A situação originária, a situação que mobiliza o pensamento é a de uma ancestralidade que, "ao nível do ser", nunca vem a ser presentemente, e exatamente por isso desperta no ser o seu logos, seu discurso, sua língua. "Ao nível do ser" quer dizer simplesmente que essa ancestralidade quer expressar seu acontecimento, quer ter direito à linguagem e produzir seu discurso. Exatamente aqui se deve reconhecer a diferença entre a ética e a ontologia e se recolocar a questão da filosofia primeira. Essa ancestralidade não é uma variação do ser, um ser outramente que se estenderia do passado em direção ao ser. Essa ancestralidade é uma alteridade, um outramente que ser. Digamos, um passado que é de outra natureza e que, por isso, tem condições de surpreender o ser em sua confortável posição, em sua soberania. Essa alteridade de outra natureza, estranha e estrangeira ao ser, quer, no entanto, ter direito à linguagem, e onde imediatamente detectamos o "problema de linguagem" visceral do discurso levinasiano - o outramente que ser que, no entanto, é - flagramos a usurpação do ser justificando-se a si mesmo.

Como se justifica o ser ou o fato de que se é, eis a difícil questão que produz o nosso mal-estar, e do qual deriva o mal-estar da política. O discurso levinasiano dispõe a responsabilidade como justificativa do direito de ser. É preciso responder pelo direito de $\operatorname{ser}^{4}$ para que a ontologia não seja um discurso encantatório. É preciso garantir que a ética seja sempre a primeira lição a ser tomada, isso significando

\footnotetext{
4 “... ser como má consciência; ser em questão, mas também voltado à questão, ter que responder nascimento da linguagem; ter que falar, ter que dizer eu [je], ser na primeira pessoa, ser eu [moi] precisamente; mas, desde então, na afirmação de seu ser de mim [moi], ter que responder pelo seu direito de ser". (LEVINAS, Emmanuel. Entre nous. Essais sur le penser-à-l'autre. Paris: Grasset, 1991. p. 139). A linguagem não poderia nascer senão como resposta, ter que falar..., ter que dizer eu..., muito anteriormente à função nomeadora e ordenadora das coisas, muito anteriormente a sua natureza ontológica, e ainda que esta fosse imediatamente visível, haveria uma natureza outra, uma necessidade prévia, imperativa, ter que responder, e a partir de então, e somente por isso, poder nomear e conter as coisas. Em Levinas a linguagem testemunha uma vocação ética.
} 
efetivamente que ela não possa ser jamais negociada, que ela não entre no jogo ontológico. O desafio do discurso ético é, portanto, burlar o programa de linguagem que facilmente se armará contra ele. Porque o discurso ético será um discurso de crítica à ontologia e porque a linguagem filosófica é, desde sempre, programada ontologicamente. Como proceder num discurso de crítica ontológica tendo que recorrer inevitavelmente a conceitos forjados pela ontologia, esse é o desafio formal da filosofia levinasiana. Como mostrar por meio da linguagem, portanto como dizer, que a ética é materialmente diferente da ontologia, que ambas não partilham a mesma natureza.

É preciso radicalizar o discurso ético. Mas se radicalizar é levar mais a sério o que se quer dizer, é também buscar as raízes, portanto, um fundamento. Aqui se inscreve uma virada na história do discurso ético, e é Levinas o artífice dessa virada. Para fora das raízes do logos ontológico não há mais raízes, não há onde, não há lugar. É nessa região sem fundamento, sem chão, que a linguagem radical da ética encontra seu lugar ou seu não-lugar. Se quisermos radicalizar o discurso da ética teremos que afirmar que a verdadeira linguagem da ética é desenraizada e desenraizante. Quando Levinas afirma que o dizer precede o dito ${ }^{5}$, que a responsabilidade por outrem é um puro dizer sem dito, é exatamente isso que se quer dizer: um estado arrancado de raízes, um estado u-tópico, sem lugar. Mas que não se entenda por u-topia algo que não se pode realizar, algo impossível. Ou, de outra forma, que se entenda afirmativamente o impossível dessa utopia, que ele escape de sua pura negatividade. Afirmar esse impossível utópico da ética é engajar-se para criar condições e realizalo, sem que isso possa ser previsto ou calculado, ou seja, sem que isso esteja sob

\footnotetext{
5 "O sujeito no Dizer se aproxima do próximo se ex-primindo, no sentido literal do termo, se expulsando fora de todo lugar, não habitando mais, não pisando nenhum solo. O Dizer descobre, além de toda nudez, o que aí pode restar de dissimulação sob a exposição de uma pele despida. Ele é a respiração mesma dessa pele antes de toda intenção". (LEVINAS, Emmanuel. Autrement qu'être ou audelà de l'essence. Paris: Kluwer Academic, 2001. p. 83). O dizer é, portanto, uma suspensão que acusa o estado de usurpação que constitui o nosso domínio sobre a terra. É certo que habitamos, sobretudo porque afirmamos o nosso estado de habitação, porque tal pertence à visibilidade histórica que nos constitui. Mas no próprio decorrer da história, porque falamos ao outro, porque nos pronunciamos, suspendemos o enraizamento histórico. Não estaria o próprio decorrer da história condicionado a esse desenraizamento? O Dizer engendra um tempo que interrompe o habitar e o pertencer históricos.
} 
controle. Um estado arrancado de raízes, portanto desenraizado, que é ao mesmo tempo, na modalidade mesma de sua essência, como diria Levinas, um estado que provoca o arrancar das raízes, portanto um estado desenraizante. Que se tome por raízes toda forma ontológica de se localizar na linguagem apoderando-se dela, dominando as formas de dizer ou naturalizando seus ditos como se fossem imperativos.

Se fosse possível alguma espécie de topografia, diríamos que a linguagem da ética é desértica, e, aliás, muito próxima da espiritualidade nômade. $\mathrm{O}$ deserto não permite o enraizamento, qualquer localização é necessariamente provisória, pois os pontos de referência estão em permanente mobilidade. Por isso é impossível uma descrição do deserto. Da mesma forma, a linguagem da ética não permite ser descrita. No deserto, em algum lugar flutuante, lugar impossível, se estende a tenda nômade. Mas ela não é uma casa, pois uma vez que não pode se firmar em alicerces (fundamentos), não pode dominar, não pode tomar posse do lugar. Digamos que a tenda é a proto-casa que deve inspirar constantemente a casa, o espírito da casa, ou melhor ainda, aquilo que justifica a casa em seu direito de ser, mas justifica constantemente, como se deve justificar uma obra inacabada. A casa deveria evocar a memória da tenda nômade. Pois é justamente nessa morada provisória onde vamos encontrar uma espécie de laboratório da linguagem ética.

Edmond Jabès conta uma história interessante em seu último livro ${ }^{6}$ a respeito dessa lição de ética da cultura nômade. Numa travessia pelo deserto uma tempestade interrompe o caminho de dois viajantes que, depois de uma longa espera, são acolhidos por uma caravana de beduínos. Eles dormem na tenda, esperam o tempo melhorar e, no dia seguinte, seguem com o grupo até seu destino. Num gesto de agradecimento pela acolhida, eles resolvem comprar tecidos para oferecer aos beduínos que eles querem reencontrar no dia seguinte. $\mathrm{E}$ aqui ocorre a grande lição: quando retornam são recebidos como dois estranhos, como se não tivesse havido recentemente qualquer encontro. Pois, por mais conhecidos que possam ser, os

\footnotetext{
${ }^{6}$ JABÈS, E. Le livre de l'hospitalité. Paris: Gallimard, 1991. p. 81-85.
} 
visitantes da tenda nômade não podem ser reconhecidos, é preciso que permaneçam estrangeiros para que nenhuma tentação de reconhecimento, de identificação, possa encobrir a essencial estrangeiridade que envolve o encontro e a acolhida. É preciso que permaneçam estrangeiros, que se sintam estrangeiros, ainda que a custa de um fingimento, um jogo de cena. Como se dissessem 'não podemos jamais esquecer que somos todos estrangeiros uns para os outros', pois esquecê-lo é correr o risco de amortecer o compromisso ético que sente quem tem sob os pés o deserto. ${ }^{7}$

Tudo o que se precisa entender pela palavra ética está nesse jogo de cena da tradição beduína: esquecer ou fingir esquecer que se conhece aquele que chega ${ }^{8}$. Todo conhecimento, do qual deriva o reconhecimento, é necessariamente posterior, é depois. Não é somente de outra natureza - a ética como sabedoria distinta de toda ordem do saber - mas é anterior. Aqui mais uma dificuldade precisa ser observada. Quando falamos levinasianamente que a ética é anterior, uma vez que é filosofia primeira, quando falamos que a ética antecede a ontologia e toda ordem de conhecimento, e também a política e suas instituições, é preciso ter em conta que não se trata de uma temporalidade cronológica ou crono-tópica. Não é isso primeiro e depois aquilo no sentido corrente. É preciso ter em conta a ideia muito levinasiana de imemorialidade e diacronia $a^{9}$. O conhecimento é um instrumento a serviço e não um horizonte que condiciona e determina os seus arredores, muito embora tudo leve a

\footnotetext{
${ }^{7}$ Cf. meu ensaio Edmond Jabès e a hospitalidade da letra, In: FARIAS, A. B. Poéticas da hospitalidade ensaios para uma filosofia do acolhimento. Porto Alegre: Zouk, 2018. p. 99-107.

8 "Se nosso anfitrião nos havia recebido fingindo não nos conhecer, era para marcar que nós permanecíamos, um e outro, a seus olhos, viajantes anônimos a quem se deveria honrar enquanto tais, em nome da ancestral hospitalidade de sua tribo, pois, de outro modo, nossa visita improvisada poderia parecer rapidamente com efêmeros reencontros". (JABÈS, op. cit., p. 85. Tradução livre)

9 "O imemorial não é o efeito de uma falha de memória, de uma incapacidade de superar os grandes intervalos do tempo, de ressuscitar os passados mais profundos. É a impossibilidade, para a dispersão do tempo, de se reunir em presente - a diacronia insuperável do tempo, o além do Dito. É a diacronia que determina o imemorial, não é uma falha da memória que constitui a diacronia". (LEVINAS, 2001, p. 66. Tradução livre). Uma temporalidade linear ou apenas histórica não dá conta dessa significação ou significância ética levinasiana. Teríamos que supor que toda nossa forma de significar se conformasse a alguma espécie de representação. A metafísica da representação e da presença encontra em Levinas uma crítica contundente: "Por trás do ser e sua mostração, desde já se escuta a ressonância de outras significações esquecidas na ontologia e que solicitam pesquisa" (LEVINAS, 2001, p. 67), e é de tal pesquisa que justamente depende o discurso ético.
} 
crer que o saber ordena toda realidade a sua medida. E, de fato, isso parece ser o óbvio. O pensamento diacrônico desequilibra a obviedade do saber a determinar o ordenamento do mundo, porque denuncia o cinismo de sua razão. Uma situação ética resiste a esse ordenamento, embora possa tal ordenamento fazer de conta que nada está acontecendo para além de seu horizonte. Admitir a diacronia é não se crer total e encerrado, ou adequado a si mesmo. É não ser indiferente ao outro. E não ser indiferente ao outro é compreender que o outro é outro não por ser ainda desconhecido, mas por ser desde sempre não conhecível. ${ }^{10}$

Como esse não conhecível originário deve figurar no ordenamento ontológico do mundo, eis a questão que deve suscitar a lição ética a ser constantemente retomada para que a política e suas instituições transcendam sua razão bélica e cínica.

Como ou por onde justificar a razão de ser da política, essa ontologia ordenadora do mundo, mas já não estamos falando da política que é basicamente a instrumentalização do cinismo, mas de uma política atravessada por uma incondicionalidade ética. Uma política que não tenha outra saída senão a de realizar o imperativo dessa incondição ética. Uma política que acolha heteronomamente - ou seja, sem chance de recusar - o compromisso de retomar constantemente a primeira e mais importante palavra, a ética, é uma política que não pode jamais se contentar com sua própria forma; não pode se reduzir às próprias condições. Uma política movida por uma constante e invencível tarefa: justificar sua razão de ser. Que a política seja atravessada por uma irrecusável responsabilidade, muito antes de ser o campo de realização de possibilidades previsíveis ou calculadas, é uma exigência que deriva de sua incondição ética. Mas, novamente, vamos atentar para o sentido diacrônico desse antes da incondicionalidade ética.

O campo de realização de possibilidades, não esqueçamos, é o campo da ação enquanto tomada de decisão. Essa anterioridade diacrônica quer dizer que tudo o que há de mais urgente deve governar a tomada de decisão. Que ela, a decisão em vias de

10 "Certamente, o Outro que se anuncia não possui este existir, como o possui o sujeito; seu domínio sobre meu existir é misterioso; não desconhecido, mas inconhecível, refratário a toda luz". (LEVINAS, Emmanuel. Le temps et l'autre. Paris: PUF, 2004. p. 63). 
ser tomada, não tenha outra saída senão a de responder a esse sentido de urgência que não cessa de lhe ocorrer porque não depende do juízo a que a decisão poderá sempre estar submetida: eis o que significa incondição ética. O nosso julgamento, quase sempre negativo, dirigido à política, compartilha com a política o horizonte histórico e ontológico. É preciso que hajam certas condições já bem sedimentadas para que o julgamento possa se articular enquanto discurso, inclusive para que possa ser reconhecido. O sentido de responsabilidade que comanda a decisão prestes a ser tomada, não pertence ao horizonte histórico que dará à decisão sua forma: eis o que significa anterioridade diacrônica da ética face à política, face à ontologia, face à história. Que o nosso julgamento, sempre histórico, expresse de alguma forma o desejo de que a decisão política realize o improvável; que tenhamos e exerçamos, também através de nosso poder de julgar, o direito de exigir da ação política o impossível, significa que de alguma forma conhecemos o que há de mais urgente a se fazer.

Evidentemente que partilhamos da ideia de ação política elaborada por Hannah Arendt: a capacidade de realizar, pela via do discurso, pela responsabilidade que concerne àquele que se pronuncia publicamente, o improvável. Deliberadamente, escrevemos responsabilidade em lugar de liberdade, como seria mais esperado para evocar o significado que Hannah Arendt dá ao termo política. Mas certamente que dá no mesmo. Em seu sentido mais estrito, o conceito de liberdade política coincide com o conceito de responsabilidade política. Seria essa a vocação de uma existência política. Sabemos que Arendt recorre ao conceito de natalidade para fundar sua concepção de política: aquele que nasce introduz no mundo, por sua própria conta, o improvável, o imprevisível, o impossível. E a quem, de direito, contestar 'se ocorreu, de alguma forma isto foi previsto; ou, se aconteceu é porque foi possível de acontecer, era provável que acontecesse' é preciso dizer: não necessariamente, tudo que se pode prever, a racionalidade científica que acredita comandar o nascimento de alguém, desconhece o aspecto mais importante desse evento, por isso não o controla: sua incondicionalidade. Quem nasce introduz no mundo uma incondicionalidade, e isto não é algo que uma ciência possa prever, não 
é de natureza cognitiva. Mas a questão que interessa aqui é entender o que significa o atravessamento da política por esse caráter incondicional da natalidade. Diz Arendt que é porque nascemos, porque irrompemos no mundo, que somos capazes de realizar o improvável. Carregamos como que uma herança de nosso próprio nascimento: a capacidade de surpreender o mundo com novos eventos, a capacidade mesmo de realizar milagres (no sentido obviamente não religioso) ou de efetivamente iniciar algo novo. É precisamente essa capacidade que atesta nossa vocação para o político. Tomar iniciativa ou ser capaz de agir é, segundo essa concepção, algo natural, no sentido de que carregamos isso ou de que é esperado que o façamos, embora permaneça na ordem do inesperado, do imprevisível, aquilo que realizamos quando agimos. Da mesma forma como o nascimento inaugura a cada vez um novo início, a ação política genuína traria de volta essa capacidade de fazer acontecer um novo início. ${ }^{11}$

E aqui me permito uma modulação interpretativa: por novo início entendo um tempo absolutamente singular, ou seja, que não pode corresponder senão a ele mesmo, e sendo assim, a ação política autêntica, genuína, essa ação que carrega a memória do acontecimento inaugural da natalidade, só pode ser uma diacronia. $\mathrm{O}$ tempo singular e diacrônico desse novo início é a tarefa constantemente retomada, fatalmente inacabada ou, como diria Derrida, passível de ser desconstruída, de nossa responsabilidade ética. Não somente passível de ser desconstruída, mas estruturalmente ou ontologicamente constituída de tal passividade. Esse tempo ético não sincroniza com o tempo histórico da política, entendida no sentido macro, no sentido do direito, das instituições, mas em sua espectralidade diacrônica, em sua

\footnotetext{
11 "O novo sempre acontece em oposição à esmagadora possibilidade das leis estatísticas e à sua probabilidade que, para todos os fins práticos e cotidianos, equivale à certeza; assim, o novo sempre aparece na forma de um milagre. $\mathrm{O}$ fato de o homem ser capaz de agir significa que se pode esperar dele o inesperado, que ele é capaz de realizar o infinitamente improvável. E isso, mais uma vez, só é possível porque cada homem é único, de sorte que, a cada nascimento, vem ao mundo algo singularmente novo. Desse alguém que é único pode-se dizer verdadeiramente que antes dele não havia ninguém. Se a ação, como início, corresponde ao fato do nascimento, se é a efetivação da condição humana da natalidade, o discurso corresponde ao fato da distinção e é a efetivação da condição humana da pluralidade, isto é, do viver como um ser distinto e único entre iguais." (ARENDT, Hannah. A condição humana. Rio de Janeiro: Forense Universitária, 2014. p. 222-223).
} 
ancestralidade pré-original, ordena ou condiciona o tempo político a um perpétuo recomeço. De outra maneira, como entender que há um movimento, um processo histórico na ordem da política e das leis? Lembrando a Segunda consideração extemporânea de Nietzsche, a respeito da relação entre vida e história, é preciso supor que o processo histórico da política esteja condicionado a um estado aistórico ${ }^{12}$ da ação política. Tal estado não seria convergente com o tempo diacrônico e imemorial da ética? O tempo diacrônico da ética e da ação política é o tempo aistórico por onde o movimento da vida deixa passar algo que ainda não foi escrito, algo em que não se pode reconhecer qualquer consideração para com a história, e dessa forma algo que corre o máximo risco: pois ele tanto pode realizar a maior das injustiças, quanto pode ser a própria sorte da justiça. Uma espécie de atrevimento ou de loucura mesmo é preciso afirmar nesse ato improvável. Não haveria melhor maneira de entender o gesto amoroso. Mas que não se pense que tal gesto seja necessariamente a realização de um bem, pois no tempo diacrônico da ética e da ação política nada está prescrito. A ética da alteridade não é um moralismo ou um deontologismo. É preciso reconhecer que o amor também tem seu lado terrível.

Certamente essas ideias políticas de Hannah Arendt concordam com o entendimento levinasiano da questão, ainda que façamos aqui uma torção interpretativa (mas como poderia ser de outra forma?). Toda dificuldade parece estar traduzida nessa ideia de esperar o que não pode ser esperado, de realizar o impossível. Quase como se não pudéssemos conceber nem uma política, nem uma ética de fato. Afinal de contas, estaremos sempre fadados a realizar e a poder julgar o que realizamos. Mas o que se quer dizer com a palavra ética é justamente essa

12 "É a condição mais injusta do mundo: estreita, ingrata com o passado, cega para os perigos, surda para advertências, um pequeno redemoinho vivo em um mar morto de noite e esquecimento: e contudo é essa condição - totalmente aistórica e anti-histórica - o útero não apenas do ato injusto, mas, ao contrário, de todo ato justo; nenhum artista alcançará sua obra, nenhum general, sua vitória, nenhum povo, sua liberdade, sem antes ter querido e ansiado tal estado aistórico. (...). Assim, todo homem de ação ama seu ato infinitamente mais do que ele mereceria: e os melhores atos ocorrem em tal superabundância de amor, amor que eles, em todo caso, não deveriam merecer, mesmo se seu valor fosse inestimavelmente alto". (NIETZSCHE, Friedrich. Sobre a utilidade e a desvantagem da história para a vida - segunda consideração extemporânea. São Paulo: Hedra, 2017. p. 39-40). 
possibilidade de assumir novamente o compromisso com uma justiça anterior à justiça histórica. É impossível ser infinitamente responsável, a começar pelo fato de que a vida é uma duração que termina. Mas esse só pode ser um ponto de vista analítico ou externo; um ponto de vista para o qual o tempo é uma sucessão de instantes que vai se consumar. Se nossa referência for a própria duração da vida, o sentido dessa infinitude é a de um tempo que nunca termina de começar. É como se descobríssemos o próprio tempo em sua indeterminabilidade estrutural.

O impossível ou o improvável da ação política, ou ética, é simplesmente a afirmação de uma potência que a história não pode registrar ou conhecer; uma potência que vai além do poder que, no fim das contas, escreve a história. O que normalmente entendemos por política passa pelo exercício do poder. Mas quem simplesmente exerce o poder, fecha o caminho por onde uma improvável ação poderia acontecer. Convêm, então, distinguir o poder da potência se quisermos conceber a ação política para além da mera retórica do poder. Um político limitado ao exercício de seu poder, um político condicionado a seu campo de possibilidades, é previsível e, exatamente por isso, impotente: não está em posse daquilo que efetivamente constitui sua vida de vivente, sua vocação para o indeterminado. Não se trata de uma contraposição, mas de uma necessidade, para a própria efetividade ético-política do poder, que ele, o poder, não inicie nele mesmo, ou não se justifique por ele mesmo. Se a política tem caráter ético, isto não está condicionado a seu poder, ainda mais se estamos pensando em termos levinasianos, (mesmo que não estritamente). É preciso sempre ter em conta o caráter de passividade que Levinas não cessa de ressaltar quando se trata de pensar a ética. $O$ poder que se justifica a si mesmo, limita o exigente conceito levinasiano de responsabilidade ética, para o qual uma heteronomia, necessariamente insuperável, não saberia conceber o agir senão como passividade, um agir passivo. O que torna a política uma ética é uma potência anterior ao poder, não contraposta, mas perfeitamente capaz de se comunicar ou de contagiar o poder político, a ponto de abrir caminho ao improvável. Novamente a ideia de anterioridade quereria dizer uma diacronia. 
A capacidade de fazer acontecer o que não se pode esperar estaria ligada, em nossa hipótese, a uma potência diacrônica, que condicionaria o poder politico a um interminável estado de justificação ética.

O conceito de potência remete a Nietzsche (Wille zur Marcht) e a Bergson (Élan vital), mas deseja provocar aqui um necessário estado de criação. Tanto em Nietzsche, quanto em Bergson vamos encontrar a ideia fundamental de uma relação intrínseca entre vida e potência, muito embora Nietzsche não restrinja o seu conceito de vontade de potência ao nível meramente orgânico, tudo o que existe, vivo ou não vivo, deve seu modo de ser a essa força ativa, a esse impulso chamado vontade de potência ${ }^{13}$. O impulso vital bergsoniano tem uma função diferenciadora, e é também uma força ativa, de expansão e afirmação da vida, portanto uma potência ${ }^{14}$. Para nossa hipótese, importa extrair desse conceito o seu caráter criador. Vejamos se não é possível chegar ao mesmo princípio diferenciador da vida pela via da ética radical de Levinas: se por ética entendemos o estado de uma responsabilidade incondicional e infinita, expressa pela urgência, anterior à escolha (portanto passiva), do acolhimento do outro, da alteridade, é esse estado incondicional o próprio impulso do vir a ser da vida. Vir a ser ou devir que levinasianamente remete ao outramente que ser.

É preciso reconhecer e destacar a radicalidade da perspectiva crítica levinasiana: os conceitos nietzscheano e bergsoniano referidos promovem uma crítica à ontologia tradicional uma vez que afirmam um perpétuo estado de vir-a-ser

\footnotetext{
${ }^{13}$ Destaco um trecho do verbete Vontade de potência, de autoria de Scarlett Marton, extraído do Dicionário Nietzsche: “(...) a todo instante, a vontade de potência, vencendo resistências, se autossupera e, nessa superação de si, faz surgir novas formas. Enquanto força eficiente, é pois força plástica, criadora. É o que revela a própria expressão vontade de potência (Wille zur Marcht): o termo Wille entendido enquanto disposição, tendência, impulso, e Marcht associado ao verbo machen, fazer, produzir, formar, efetuar, criar." (MARTON, Scarlett (org.). Dicionário Nietzsche. São Paulo: Loyola, 2016. p. 424).

14 "O élan de vida de que falamos consiste, em suma, numa exigência de criação. Não pode criar absolutamente porque encontra diante de si a matéria, ou seja, o movimento inverso ao seu. Mas apodera-se desta matéria, que é a própria necessidade, e tende a introduzir nela a maior quantidade possível de indeterminação e de liberdade". (BERGSON, Henri. A evolução criadora. Lisboa: Edições 70, 2001. p. 225).
} 
ou o devir de toda realidade; em Levinas, essa crítica vai mais longe, pois afirma uma inteligibilidade não-ontológica ao enfatizar a modalidade do discurso pelo advérbio outramente. Não se trata de ser outramente, (onde chegaríamos a uma ontologia do vira-ser?), mas outramente que ser, onde intuímos um estado transontológico de existência. Precisamente isso, tal estado, é o que vamos chamar de ética. E toda forma concreta que dermos à responsabilidade ao outro, já no plano histórico e visível da vida, remeteria a esse estado transontológico, para o qual todo chamado a ser é necessariamente problemático, insuficiente, mal resolvido. Isso não quer dizer que a ética levinasiana seja fraca ou deprimida, muito pelo contrário, exatamente por ser incondicional ela recupera o fôlego de toda potência contaminada pelo desejo de se realizar eticamente.

O que seria a política nesses termos? Para Levinas a política é a problematização ética inaugurada pela entrada do terceiro: a necessidade de pensar não apenas no próximo, mas no próximo do próximo e em todos os outros; a necessidade de igualar os desiguais. Mas essa problematização ética já não é a própria significação concreta e histórica da ética? Ou seja, pensar e realizar a ética, nos termos dessa exigência e dessa urgência, não é o mesmo que pensar e realizar a política? Mas então, porque insistir na separação e diferença desses conceitos? Tratase mais uma vez de uma diacronia: a ética deve manter-se diacronicamente anterior à política, como a memória irrecuperável de uma responsabilidade incondicional. O efeito prático desse arranjo conceitual é que a política, atravessada por essa memória ética, não pode se resolver no exercício de seu poder, não pode apenas poder. Tampouco pode abrir mão de poder, sob pena de impedir sua realização.

Criar condições para o improvável, exercer a liberdade responsável de decidir, tomar iniciativa como quem novamente inicia algo novo, eis o que poderia significar um poder político atravessado diacronicamente por uma potência ética e heteronômica.

Um poder político cuja força ou potência é paradoxalmente a irrecusável retomada de sua primeira e mais fundamental lição: a ética.

Chamamos a política anteriormente de ontologia ordenadora do mundo. O que poderia significar isso quando a política fosse a expressão de um devir ou uma 
potência ética heteronômica? O que poderia significar isso se o outramente que ser fosse o próprio motivo da política? Se a política tem a tarefa de comparar os incomparáveis, é preciso que se assuma de saída uma equivocidade estrutural. $\mathrm{O}$ mundo ordenado politicamente seria um processo permanente de construção e desconstrução, a atividade política seria a afirmação de um perpétuo começar de novo. Mas se, para retomar Hannah Arendt, esta seria a única condição realmente digna de ser chamada de humana, se é, como sugere a autora, pela capacidade de agir politicamente que nos afirmamos para além de uma existência meramente biológica ou previsível, podemos imaginar esse perpétuo reinício como nossa capacidade ou nossa potência criadora. Ordenar politicamente o mundo seria, portanto, exatamente o mesmo que criar perpetuamente as condições do mundo. Ou finalmente entender que a ontologia do mundo não poderá jamais se resolver, pois, do ponto de vista dessa exigente situação ético-política, traduzida na tarefa cotidiana da mais elevada condição humana, tratase, para nós e para o mundo, de justificar ainda o direito de ser.

\section{REFERÊNCIAS}

ARENDT, Hannah. A condição humana. Rio de Janeiro: Forense Universitária, 2014. BERGSON, Henri. A evolução criadora. Lisboa: Edições 70, 2001.

FARIAS, André Brayner de. Poéticas da substituição - ensaios para uma filosofia do acolhimento. Porto Alegre: Zouk, 2018.

FOUCAULT, Michel. Em defesa da sociedade. São Paulo: Martins Fontes, 2002.

JABÈS, Edmond. Le livre de l'hospitalité. Paris: Gallimard, 1991.

LEVINAS, Emmanuel. Totalité et infini. Essai sur l'extériorité. Paris: Kluwer Academic, 2000. Autrement qu'être ou au-delà de l'essence. Paris: Kluwer Academic, 2001. Entre nous. Essais sur le penser-à-l'autre. Paris: Grasset, 1991. 
Le temps et l'autre. Paris: PUF, 2004.

MARTON, Scarlett (org.). Dicionário Nietzsche. São Paulo: Loyola, 2016.

NIETZSCHE, Friedrich. Sobre a utilidade e a desvantagem da história para a vida segunda consideração extemporânea. São Paulo: Hedra, 2017. 